\title{
Corrigendum
}

\section{Corrigendum to "Cross-Shareholdings Structural Characteristic and Evolution Analysis Based on Complex Network"}

\author{
Xiaohong Chang ${ }^{1,2,3}$ and Haiyun Wang ${ }^{3}$ \\ ${ }^{1}$ Business School, Beijing Wuzi University, Beijing 101149, China \\ ${ }^{2}$ Postdoctoral Research Station of Business Administration, Tsinghua University, Beijing 100083, China \\ ${ }^{3}$ School of Economics and Management, Beijing Institute of Graphic Communication, Beijing 102600, China \\ Correspondence should be addressed to Xiaohong Chang; changxiaohong@emails.bjut.edu.cn \\ Received 4 June 2017; Accepted 25 July 2017; Published 13 August 2017 \\ Copyright (c) 2017 Xiaohong Chang and Haiyun Wang. This is an open access article distributed under the Creative Commons \\ Attribution License, which permits unrestricted use, distribution, and reproduction in any medium, provided the original work is \\ properly cited.
}

In the article titled "Cross-Shareholdings Structural Characteristic and Evolution Analysis Based on Complex Network" [1], there was a missing affiliation for the first author. The corrected authors' list and affiliations are shown above.

\section{References}

[1] X. Chang and H. Wang, "Cross-shareholdings structural characteristic and evolution analysis based on complex network," Discrete Dynamics in Nature and Society, vol. 2017, Article ID 5801386, 7 pages, 2017. 


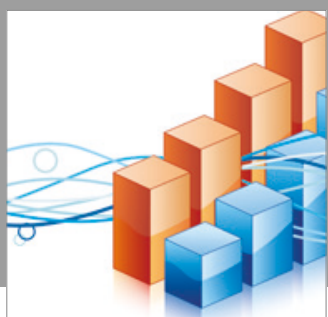

Advances in

Operations Research

vatersals

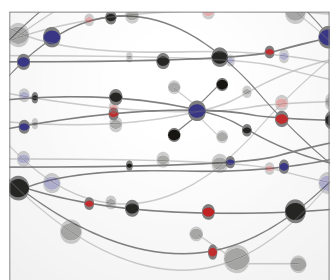

\section{The Scientific} World Journal
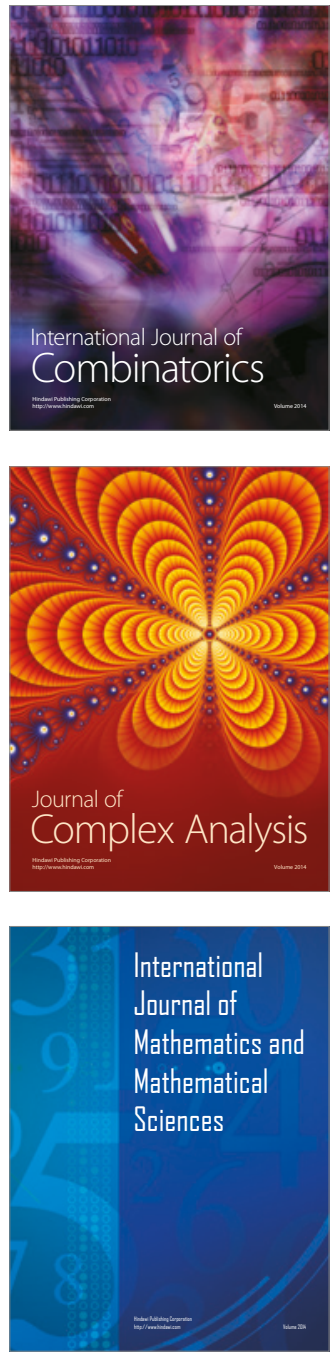
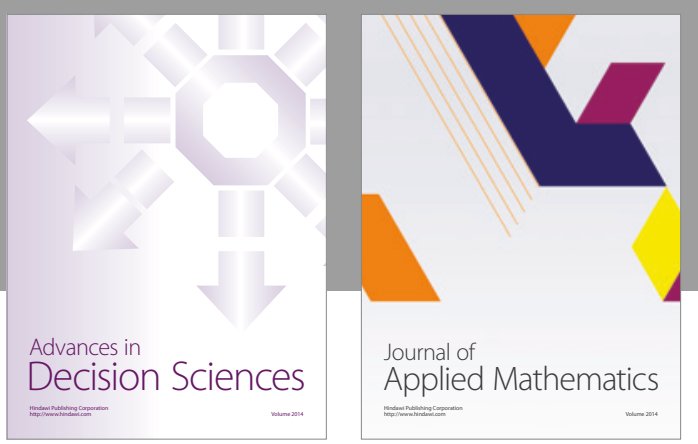

Algebra

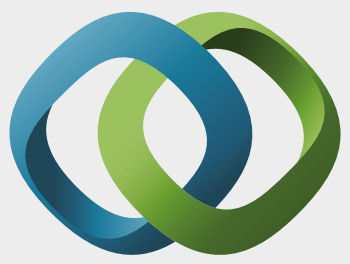

\section{Hindawi}

Submit your manuscripts at

https://www.hindawi.com


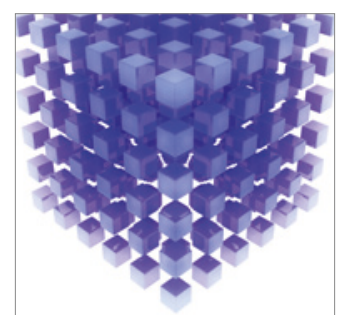

Mathematical Problems in Engineering
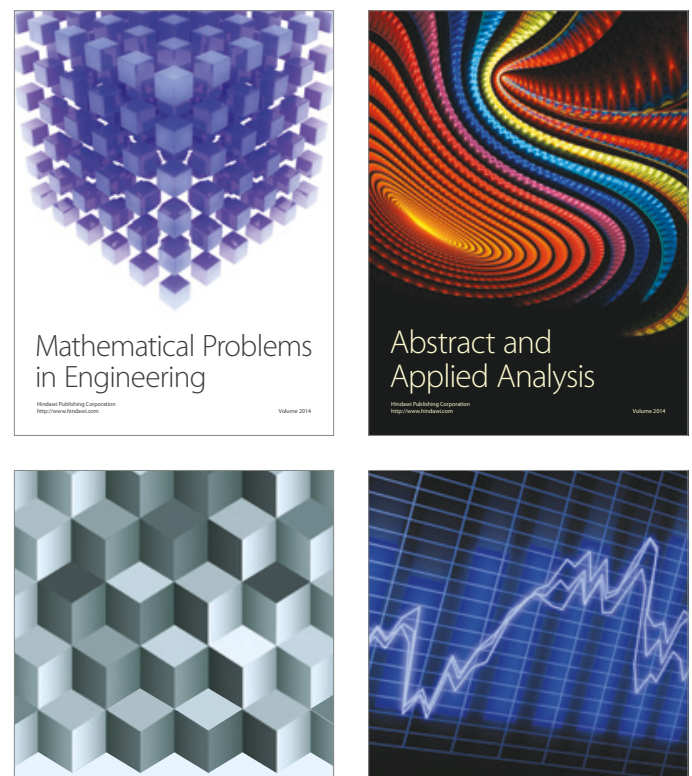

Journal of

Function Spaces

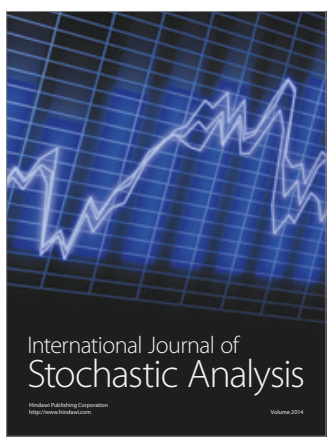

Probability and Statistics
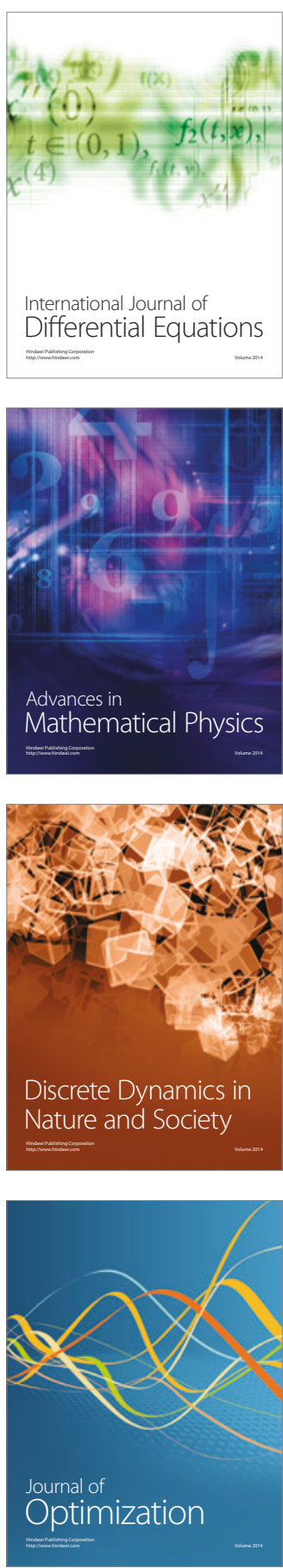